\title{
Pelatihan olah seni vokal berbasis elekton pada murid autis di SLB Negeri 1 Makassar
}

\author{
Abdul Hadis ${ }^{1}$, Mustafa $^{2}$, Usman $^{3}$ \\ ${ }^{1,2,3}$ Fakultas Ilmu Pendidikan, Universitas Negeri Makassar
}

\begin{abstract}
This Community Partnership Program (PKM) in SLBN 1 Makassar City. Theformulation problem is: disability students who a re autistic as students who experience disabilities both in terms of mental a spects an d in terms of communication disorders. But, have a number of potential that should be proud of his parents, siblings, environment, and at school community, nation and state. Potential superior in question is superior ta lent in vocal arts, music, classy call to pray, and other potentials. This fact was demonstrated by one of the students of the PLB FIP UNM Department, demonstrating a nextraordinary talent in pla ying electronic keyboards while singing (musical ta lent), even though they were very blind. In the commemoration of international disability day in the auditorium of Amanagappa, there were autistic children with ta lent in vocal arts. The external target was training in singing national anthems. The method used was lecture and training. The results achieved were the four a utistic child ren who were trained in electronic-based vocals were able to sing two national anthems, namely independence d ay a nd cheers.
\end{abstract}

Key words: vocalarts processing, a utistic student, SLBN 1 Makassar

\section{PENDAHULUAN}

Mencermati fakta di masyarakat, yaitu komunitas anak disabilitas autis, yang dulu dijuluki sebagai anak berkebutuhan khusus, masih termarginalkan di masyarakat, sekalipun tidak sedikit dari jumlah anak disabilitas yang autis tersebut menunjukkan prestasi yang fenomenal dan spektakuler pada bidang-bidang tertentu. Bahkan diantara mereka, khususnya yang tergolong anak yang menyandang tunanetra baik yang buta rapat maupun yang lemah penglihatan berhasil mencapai gelar doktor dengan prestasi yang gemilang. Selain itu, tidak sedikit jumlah anak tunanetra yang menunjukkan prestasi menonjol di bidang seni musik, khususnya dalam memainkan melodi, piano, drum, gitar, bas, dan instrumen musik lainnya (Subu, 2017).

Selain itu, tidak sedikit jumlah anak yang menyandang disabilitas (termasuk yang autis), menunjukkan arya nyata di masyarakat berupa membuat peralatan rumah tangga, yang memiliki nilai jual secara ekonomi, dan sangat membantu dalam memenuhi keperluan rumah tangga bagi masyarakat. Namun yang menjadi permasalahan ialah, masih sangat minim jumlah anak yang diabilitas autis yang menaruh minat yang besar sebagai vokalis karena mereka tidak diberdayakan oleh masyarakat yang mampu, baik mampu secara ekonomi maupun mampu secara pendidikan (Hadis, 2017). Oleh karena itu,sangat urgen dilakukan "Pelatihan olah seni vokal berbasis elekton kepada murid autis di SLB Negeri 1 Makassar" untuk memberdayakan mereka di bidang olah seni vokal, sehingga mereka akan dapat mendiri dalam kehidupan keluarga, sekolah, dan masyarakat.

Masalah kurangnya perhatian orangtua, masyarakat, dan pemerintah dalam usaha untuk memberdayakan anak disabilitas autis yang sekolah di SLBN 1 Makassar), di bidang kehidupan masyarakat, khususnya di bidang kesenian, yaitu berperan sebagai vokalis, juga dialami oleh SLBN 1 Makassar sebagai Pusat Pendidikan Khusus dan Layanan Khusus. Masalah inilah yang akan dicarikan solusinya melalui pelaksanaaan kegiatan pengabdian kepada masyarakat ini. 


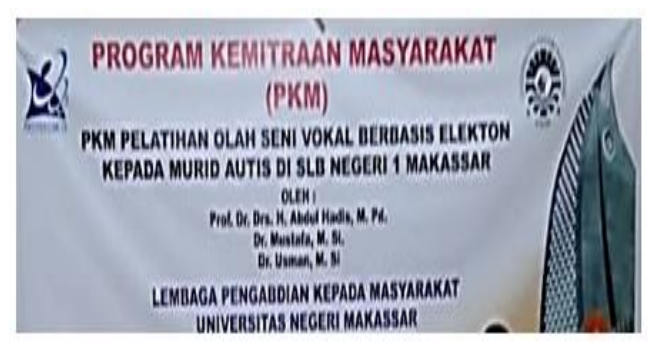

Gambar 1. Spanduk Kegiatan PKM

\section{METODE PELAKSANAAN}

1. Agar anak autis memiliki pengetahuan tentang lagu yang akan dilatihkan, maka digunakan metode ceramah.

2. Agar anak autis memiliki penghapalan tentang lagu yang akan dilatihkan, maka digunakan metode pelatihan dan

3. Agar anak autis memiliki penguasaan tentang lagu yang dilatihkan dengan irama musik elekton, maka digunakan metode pelatihan secara berulang kali dan intensif.

\section{HASIL DAN PEMBAHASAN}

A. Memperkenalkan Lagu untuk Dihafal dengan Melihat Teks Lagu

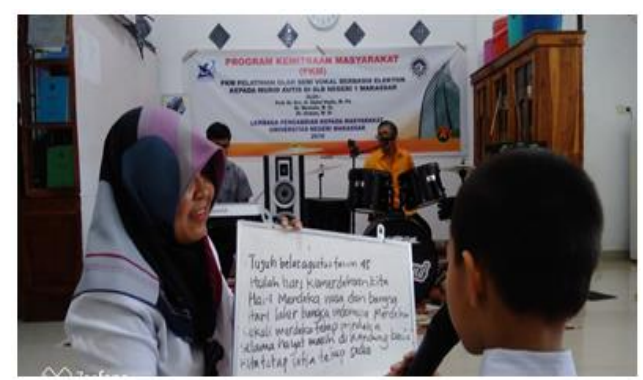

Gambar 2. Latihan menghafal naskah lagu

B. Latihan Mendengarkan Irama Musik Secara Berkelompok

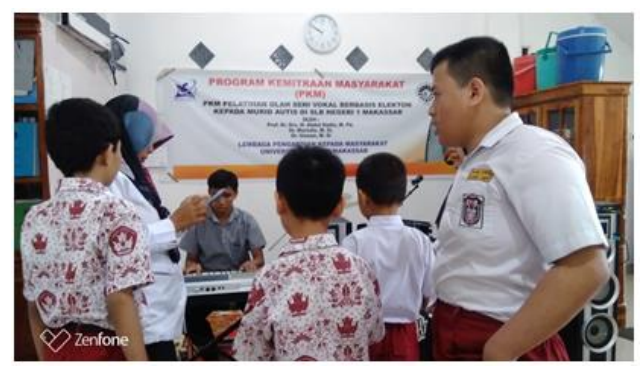

Gambar 3. Mendengarkan irama musik secara berkelompok
C. Latihan Menyanyi Secara Berkelompok untuk Empat Anak Autis

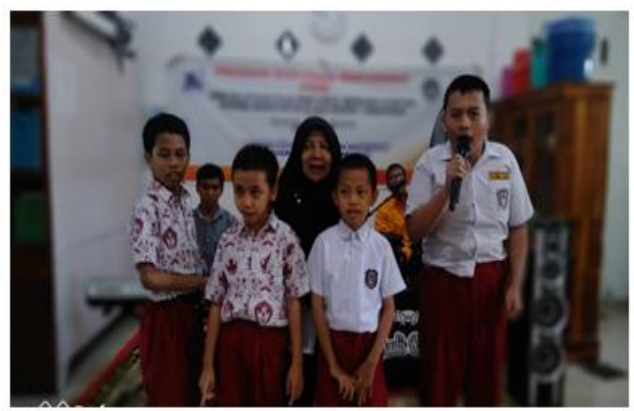

Gambar 4. Latihan menyanyi secara berkelompok untuk empat anak autis

D. Latihan Menyanyi Secara Sendiri dari Ketiga Anak Autis
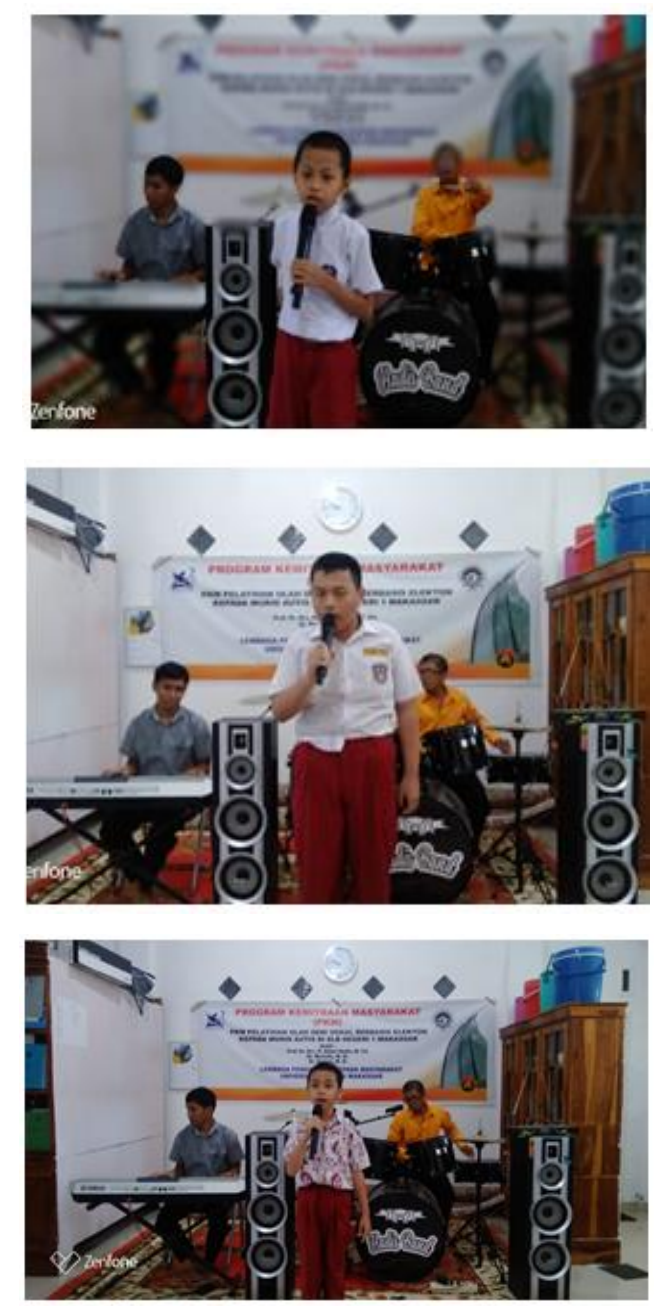

Gambar 5. Latihan menyanyi secara sendiri dari ketiga anak autis 


\section{KESIMPULAN}

Hal-hal yang dapat disimpulkan yaitu:

1. Mitra anak autis memiliki kemampuan dalam membaca naskah lagu kebangsaan yang akan dihapal.

2. Mitra anak autis memiliki kemampuan dalam menghapal naskah lagu kebangsaan yang akan dilatihkan dalam olah vokal berbasis elekton.

3. Mitra anak autis memiliki kemampuan dalam mengikuti irama lagu kebangsaan yang dilatihkan kepada mereka berbasis elekton.

4. Mitra anak autis memiliki kemampuan dalam menyanyikan lagu kebangsaan yang dilatihkan kepada mereka secara baik dan benar dalam olah vokal berbasis elekton.

\section{DAFTAR PUSTAKA}

Hadis, Abdul, 2017. Anak Disabilitas Belum Diberdayakan di Lingkungan Keluarga, Sekolah, dan di Masyarakat. Makassar: Pustaka Pribadi.

Subu, 2017. Anak Disabilitas: Anak yang Berkekurangan dan Berkelebihan. Makassar: Pustaka Pribadi. 